\title{
Effects of reduced-fat diets with different fatty acid compositions on serum lipoprotein lipids and apolipoproteins
}

\author{
Antti Aro ${ }^{1, *}$, Pirjo Pietinen ${ }^{1}$, Liisa M Valsta ${ }^{1}$, Anu M Turpeinen ${ }^{1}$, Christian Ehnholm², \\ Rita M Dougherty ${ }^{3}$ and James $M$ lacono $^{3}$ \\ ${ }^{1}$ Departments of Nutrition and ${ }^{2}$ Biochemistry, National Public Health Institute, Helsinki, Finland: \\ ${ }^{3}$ Western Human Nutrition Center, US Department of Agriculture, San Francisco, USA
}

Submitted 30 October 1997: Accepted 14 January 1998

\begin{abstract}
Objective: To compare the effects on serum lipoproteins of three isocaloric diets with reduced total fat and saturated fatty acid (SFA) contents but with different proportions of monounsaturated (MUFA) and polyunsaturated fatty acids (PUFA).

Design: A low-fat diet (LF) provided 20 en\% fat, 7.9\% SFA, 7.8\% MUFA, 3.0\% PUFA; a high-PUFA diet (HP) 26 en\% fat, 7.5\% SFA, 8.2\% MUFA, 8.1\% PUFA; and a high-MUFA diet (HM) 26 en\% fat, 7.3\% SFA, 14.1\% MUFA, 3.2\% PUFA. Diets were consumed for 8 weeks in a parallel design, after 2 weeks on a habitual diet with $33-34$ en\% fat, $13-14 \%$ SFA, 12\% MUFA, 6\% PUFA, and followed by an 8-week period on habitual diet. Compliance to diet was monitored by repeated food records and weekly visits to a nutritionist.

Subjects: 45 free-living, middle-aged couples who were randomly allocated into the three diet groups; 43 men and 44 women completed the study.

Results: During the diet periods, a small but significant reduction in body weight of $0.4-1.0 \mathrm{~kg}$ was observed in all groups. Similar and significant reductions of mean weight-adjusted serum total cholesterol (4-8\%), low-density lipoprotein (LDL) cholesterol (7-11\%), and high-density lipoprotein (HDL) cholesterol (8-11\%) were observed during the diets. $\mathrm{HDL}_{2}$-cholesterol and apoprotein (apo) A-I levels were reduced whereas $\mathrm{HDL}_{3}$-cholesterol and apoA-II increased. ApoB was significantly decreased during the $\mathrm{HM}$ diet only. Serum triglycerides increased significantly during diets $\operatorname{LF}(25 \%, P<0.01)$ and $\mathrm{HP}(19 \%, P<0.05)$ but not during diet $\mathrm{HM}(5 \%, \mathrm{NS})$.

Conclusions: Reduction in the intake of total fat and saturated fatty acids reduced serum LDL-cholesterol and $\mathrm{HDL}_{2}$-cholesterol concentrations irrespective of the relative proportions of MUFA and PUFA in the diets. The results suggest that there might be some advantage in increasing the proportion of MUFA in low-fat diets, since the HM diet rich in MUFA reduced apoB and slightly attenuated the increase in serum triglycerides that is commonly associated with dietary fat reduction.
\end{abstract}

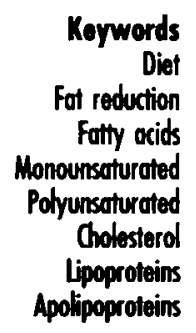

Reduction of dietary fat intake reduces serum cholesterol levels in people who consume typical Western diets ${ }^{1}$. Both low-density lipoprotein (LDL) cholesterol and high-density lipoprotein (HDL) cholesterol are generally reduced. The decrease in LDLcholesterol is due to a reduction in dietary saturated fatty acid (SFA) intake. SFA with 12-16 carbon atoms increase serum LDL-cholesterol levels while monounsaturated fatty acids (MUFA) are considered neutral and polyunsaturated fatty acids (PUFA) slightly hypocholesterolaemic ${ }^{2}$. Very large amounts of PUFA may decrease serum HDL-cholesterol ${ }^{3,4}$ but in habitual Western diets the effects of MUFA and PUFA on HDLcholesterol are generally considered neutral ${ }^{2}$. In isocaloric diets SFA also increase HDL-cholesterol levels, lauric ( $\mathrm{C} 12)$ and myristic ( $\mathrm{C} 14)$ acids more than

C16 palmitic acid ${ }^{5-8}$. Low-fat diets that are relatively rich in carbohydrates tend to increase serum triglycerides. The concept of carbohydrate-induced hypertriglyceridaemia has been known for decades ${ }^{9}$. Early studies particularly addressed the effects of different sugars on serum triglycerides ${ }^{9,10}$ but soon it became apparent that the proportional increase in carbohydrates that accompanies dietary fat reduction may also induce hypertriglyceridaemia, both in healthy ${ }^{11-13}$, hypertriglyceridaemic $^{12.14}$ and diabetic subjects ${ }^{15}$. The increase in serum triglycerides may be attenuated by concomitant weight reduction ${ }^{16,17}$, dietary fibre ${ }^{18}$ and a gradual reduction in fat intake ${ }^{19}$ and it has been suggested that the effect may be temporary and found only in short-term studies ${ }^{20}$.

The effects of the relative amounts of MUFA and 
PUFA on serum triglycerides and HDL-cholesterol during low-fat diets or reduction in fat intake are poorly known. The results of the few available studies have shown no effect on HDL-cholesterol by the amount of PUFA ${ }^{1,21,22}$ and either no difference between MUFA and PUFA ${ }^{23}$ or lower triglyceride levels by PUFA compared with MUFA ${ }^{24}$. We compared three reducedfat diets, all similarly low in SFA but containing different amounts of MUFA and PUFA, in their effects on serum lipoproteins, with particular attention to changes in HDL-cholesterol and its subfractions, apolipoproteins, and triglycerides.

\section{Material and methods}

\section{Subjects}

The subjects were couples living in the North Karelia Province in East Finland. They were contacted by advertisements in local newspapers. People who volunteered were screened for hypertension, hyperlipidaemia and diabetes, and their diets were assessed by 3-day food records. The exclusion criteria were drug therapy known to affect blood pressure or blood lipids, body mass index $>35 \mathrm{~kg} \mathrm{~m}^{-2}$, fasting blood glucose $>6.7 \mathrm{mmoll}^{-1}$, blood pressure lower than $130 /$ $80 \mathrm{mmHg}$ or higher than $170 / 100 \mathrm{mmHg}$, and low habitual fat intake $(<30 \mathrm{en} \%)$. Included were 45 couples. Three subjects dropped out at the beginning of the study, and 87 subjects, 43 men and 44 women, aged $40-65$ years, completed the study.

\section{Study design}

The study comprised a 2-week baseline period followed by an 8-week intervention period and an 8week switchback period. During the baseline and switchback periods the subjects consumed their habitual diets. For the intervention period the couples were randomly allocated by lottery into three groups of 15 couples each. Each couple was always allocated together to the same group. The groups were similar with respect to age, body mass index, serum cholesterol and blood pressure at screening (Table 1). One group consumed a very low-fat diet (LF), the other group a low-fat diet relatively high in polyunsaturated fatty acids (HP), and the third group a low-fat diet relatively high in monounsaturated fatty acids (HM). The subjects were advised to maintain their smoking habits, alcohol consumption, and level of physical activity unchanged.

The couples attended the study centre weekly for weighing and blood pressure measurements and for dietary counselling by nutritionists. There were four nutritionists, each one responsible for the counselling of subjects (couples) from all three groups. The diets were monitored by 3-day food records that were collected every second week throughout the study. The records were filled in as a diary on blank forms. The portion sizes of foods were estimated using a picture booklet of 122 photographs of foods, each with 3-5 portion sizes. The individual food records were entered into portable computers and the nutrient compositions were analysed by the computer program Micro-Nutrica (the Social Insurance Institution, Turku, Finland) before the following weekly visit to the nutritionist. The fatty acid composition of the margarines, oils and salad dressings tailor made for this study as well as the special recipes given to the subjects were added to the food composition database used by the program. Particular attention was paid to the maintenance of stable body weight. At the end of all periods, two fasting blood samples were drawn at 1-week intervals.

\section{Diets}

The intervention diets were designed to be low in total fat and SFA but to differ in the proportions of different fatty acid classes (Table 2). All diets were designed to comprise $8 \mathrm{en} \%$ as SFA. Diet LF was designed to be low in total fat (only $20 \mathrm{en} \%$ ) and PUFA. The HP and the HM diets were designed to comprise equal amounts of total fat ( $26 \mathrm{en} \%)$, the HP diet a relatively high proportion ( $8 \mathrm{en} \%)$ of PUFA and the HM diet a high proportion (14 en\%) of MUFA. Diet HP was similar to the diet of a previous dietary intervention study conducted in the same area in $1980^{25,26}$. Originally the goal for PUFA intake during the LF and HM diets was set at 2 en\%. However, it was not possible to reduce the PUFA intake to that extent by using natural foods so the goal was increased to $3 \mathrm{en} \%$. In all three diets fatty fish and foods high in potassium and dietary fibre were restricted in

Table 1 Characteristics at screening of the subjects allocated into the three groups

\begin{tabular}{lccc}
\hline & LF group & HP group & HM group \\
\hline No. of men/women & $14 / 15$ & $15 / 15$ & $14 / 14$ \\
Age, years & $52.4(6.8)$ & $51.1(6.0)$ & $49.6(6.8)$ \\
Body mass index $\left(\mathrm{kg} \mathrm{m}^{-2}\right)$ & $27.1(3.48)$ & $26.3(3.22)$ & $26.8(3.79)$ \\
Serum cholesterol $\left(\mathrm{mmol}^{-1}\right)$ & $6.02(1.04)$ & $5.67(1.02)$ & $5.95(0.93)$ \\
Systolic blood pressure $(\mathrm{mmHg})$ & $138.6(14.39)$ & $139.9(16.47)$ & $137.6(16.42)$ \\
Diastolic blood pressure $(\mathrm{mmHg})$ & $83.0(9.19)$ & $85.60(7.55)$ & $83.8(0.93)$ \\
\hline
\end{tabular}

Values are mean (SD). 
Table 2 Lipid composition of the diets

\begin{tabular}{|c|c|c|c|c|c|}
\hline & \multirow[b]{2}{*}{ Total fat $(e n \%)$} & \multicolumn{3}{|c|}{ Fatty acids (en\%) } & \multirow[b]{2}{*}{ Cholesterol (mg day ${ }^{-1}$ ) } \\
\hline & & SFA & MUFA & PUFA & \\
\hline $\begin{array}{l}\text { LF diet } \\
\text { Baseline } \\
\text { Intervention }\end{array}$ & 34.7 & 13.4 & 12.1 & 6.3 & 336 \\
\hline $\begin{array}{c}\text { designed } \\
\text { measured } \\
\text { Switchback }\end{array}$ & $\begin{array}{l}20.0 \\
20.4 \\
33.4\end{array}$ & $\begin{array}{r}8.0 \\
7.8 \\
13.1\end{array}$ & $\begin{array}{r}8.0 \\
7.7 \\
11.5\end{array}$ & $\begin{array}{l}3.0 \\
3.0 \\
6.1\end{array}$ & $\begin{array}{l}289 \\
362\end{array}$ \\
\hline $\begin{array}{l}\text { HP diet } \\
\text { Baseline } \\
\text { Intervention }\end{array}$ & 32.8 & 13.0 & 11.6 & 5.5 & 305 \\
\hline $\begin{array}{c}\text { designed } \\
\text { measured } \\
\text { Switchback }\end{array}$ & $\begin{array}{l}26.0 \\
26.0 \\
34.1\end{array}$ & $\begin{array}{r}8.0 \\
7.6 \\
13.5\end{array}$ & $\begin{array}{r}8.0 \\
8.1 \\
11.9\end{array}$ & $\begin{array}{l}8.0 \\
8.3 \\
6.0\end{array}$ & $\begin{array}{l}270 \\
338\end{array}$ \\
\hline $\begin{array}{l}\text { HM diet } \\
\text { Baseline } \\
\text { Intervention }\end{array}$ & 34.5 & 14.7 & 11.4 & 5.6 & 311 \\
\hline $\begin{array}{c}\text { designed } \\
\text { measured } \\
\text { Switchback }\end{array}$ & $\begin{array}{l}26.0 \\
26.5 \\
34.9\end{array}$ & $\begin{array}{r}8.0 \\
7.2 \\
14.5\end{array}$ & $\begin{array}{l}14.0 \\
14.0 \\
12.1\end{array}$ & $\begin{array}{l}3.0 \\
3.2 \\
5.5\end{array}$ & $\begin{array}{l}278 \\
369\end{array}$ \\
\hline
\end{tabular}

order to reduce differences between the diets in fishderived fatty acids and dietary factors that affect blood pressure.

The subjects purchased their food from local supermarkets but certain experimental food items (margarine, oil, and salad dressing, manufactured by Unilever Research Laboratorium, Vlaardingen, The Netherlands) with specially tailored fatty acid composition, and some low-fat foods like fat-free milk, low-fat cheese and lean meat products were provided free of charge to the participants. To facilitate the adoption of the diets, written advice on how to reduce fat in cooking together with a recipe booklet were distributed to the subjects during the intervention period. Portion sizes of fatcontaining foods were given at nine energy levels between 7 and $15 \mathrm{MJ} \mathrm{day}^{-1}$ for each diet. The subjects recorded in daily diaries the consumption of the margarine, oil and salad dressing, deviations from the prescribed diet, intercurrent illnesses and the occasional use of drugs.

\section{Determinations}

The subjects were weighed weekly in light indoor clothing with the same scale. The blood samples were centrifuged and serum for lipid assays was stored at $+4^{\circ} \mathrm{C}$ until analysed within 3 days. Samples for other analyses were frozen immediately and stored at $-70^{\circ} \mathrm{C}$. Lipoproteins were fractionated with ultracentrifugation as described previously ${ }^{27,28}$. Solution densities $\left(d<1.006 \mathrm{~g} \mathrm{ml}^{-1}, 1.006<d<1.063 \mathrm{~g} \mathrm{ml}^{-1}, 1.063<d\right.$ $<1.125 \mathrm{~g} \mathrm{ml}^{-1}$, and $d>1.125 \mathrm{~g} \mathrm{ml}^{-1}$ for very lowdensity lipoproteins (VLDL), LDL, $\mathrm{HDL}_{2}$, and $\mathrm{HDL}_{3}$, respectively) were adjusted with potassium bromide, and the centrifugations were done in a type TFT 45.6 rotor (Kontron Instruments, Zurich, Switzerland) using a Beckman Model L preparative ultracentrifuge
(Beckman Instruments, Palo Alto, California). Recoveries of lipoprotein cholesterol were 87.6, 88.0 and $87.4 \%$ of serum total cholesterol in the analyses of the baseline, intervention and switchback periods, respectively. No adjustments for recovery were done. Cholesterol and triglyceride concentrations of whole serum, total HDL (after precipitation with dextran sulphate and $\mathrm{MgCl}_{2}$ ), and the lipoprotein fractions were determined by enzymatic methods (kits of Boehringer-Mannheim GmbH, Mannheim, Germany). Apolipoproteins A-I, A-II and B were analysed by immunoturbidometric methods ${ }^{29}$. With the exception of body weight and some dietary intake data necessary for increasing adherence to the diets, the subjects were kept unaware of the results before the end of the study.

\section{Statistical metbods}

For all statistical analyses, the repeated measures analysis of covariance was used ${ }^{30}$. The reported means, standard errors and $P$-values are based on these models either as contrasts or least squares (LS) means. IS means are calculated as predictions from the model using mean values for all covariates. The sAs MIXED procedure was used in the analyses. No adjustments were made for multiple comparisons. The serum and lipoprotein lipid values were adjusted for baseline weight and change of body weight. Triglyceride $P$-values were calculated after logarithmic transformation. The results are expressed as least squares means and standard errors (SEM).

\section{Results}

Diets and body weigbt

According to the repeated 3-day food records, the 


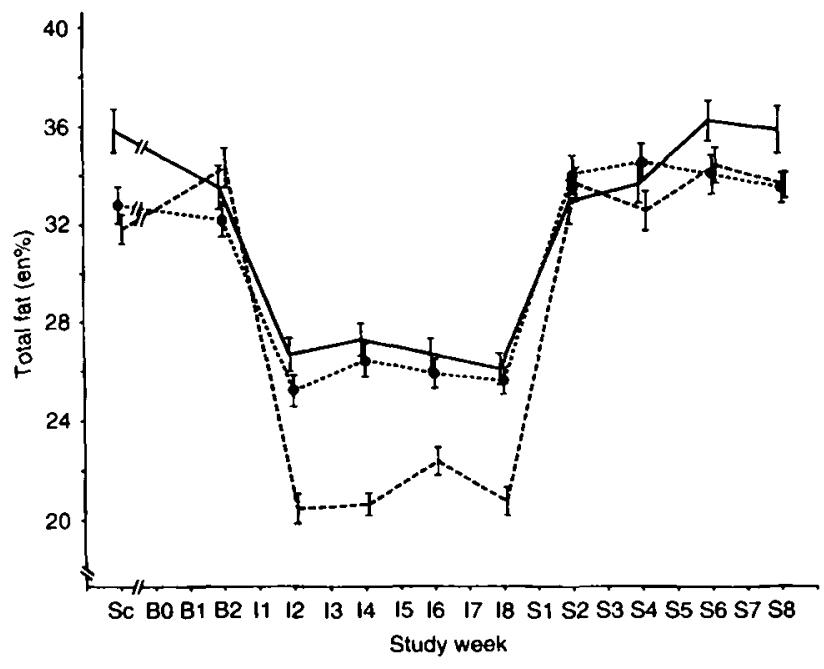

Fig. 1 Total fat intake (mean \pm SEM), as measured by repeated 3day food records during the study periods (Sc, at screening; B, baseline; I, intervention; S, switchback) in the thre日 groups (- - -

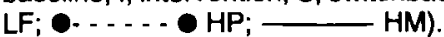

baseline and the switchback diets were very similar in the three groups, with $32.8-34.9 \mathrm{en} \%$ from fat and without differences between the groups in the proportions of SFA, MUFA and PUFA (see Table 2). During the intervention periods the goals for each diet were well achieved. The total fat intake was reduced according to the study design (Fig. 1), the proportion of SFA was reduced to levels between 7.2 and $7.8 \mathrm{en} \%$ in all diets, and the goals for the relatively high intakes of MUFA and PUFA were exactly reached in the corresponding HM and HP diets (see Table 2). Although the proportion of carbohydrates from total energy intake increased, the dietary fibre intake remained essentially unchanged. It was $27.7,26.2$ and $26.8 \mathrm{~g} \mathrm{day}^{-1}$ on the LF, HP and HM diets, respectively $\left(27.6,27.8\right.$ and $27.2 \mathrm{~g} \mathrm{day}^{-1}$ on the baseline diet in the respective groups). The repeated food records indicated good adherence to the prescribed diets throughout the 8-week intervention period (results not shown). The proportion of linoleic acid in serum cholesterol esters, measured by gas-liquid chromatography, increased from 51.2 to $56.6 \%$ of fatty acids during the HP diet and declined to $46.1-46.4 \%$ during the other two diets. Oleic acid increased from 19.1 to $26.0 \%$ during the HM diet, these changes also reflecting adherence to the diets.

Despite all efforts to counteract weight loss, a small reduction in mean body weight was observed in all three groups during the intervention period but not during the switchback periods (Table 3 ). The amounts, between 0.4 and $1.0 \mathrm{~kg}$, were clinically irrelevant and of the same order in all groups but, since the changes were statistically significant, all values were adjusted for baseline body weight and change of body weight from baseline.

\section{Lipoprotein lipids and apolipoproteins}

Compared with the baseline period, serum total cholesterol-, LDL- and HDL-cholesterol concentrations were similarly and significantly reduced during all three intervention diets (see Table 3 ). $\mathrm{HDL}_{2}$-cholesterol levels were reduced and $\mathrm{HDL}_{3}$-cholesterol levels increased during all three diets. Serum triglycerides were significantly increased during the LF and HP diets but not during the HM diet (see Table 3). The change of triglycerides from baseline to intervention was higher on the LF diet $(25 \%)$ than on the HM diet $(5 \%, P<0.05)$ while the response during the HP diet was intermediate (19\%). Serum VLDL-cholesterol was also significantly increased on the LF diet, and the response on the HM diet was significantly lower. Most values returned to baseline levels during the switchback period, with the exception of LDL-cholesterol and triglycerides after the LF and HP diets.

ApoB concentrations were significantly reduced by the HM diet but the changes during the LF and HP diets were non-significant. ApoA-I concentrations were similarly reduced and apoA-II concentrations increased during all three intervention diets (Table 4).

\section{Discussion}

\section{Main results}

The three low-fat diets showed quite similar effects on serum and lipoprotein cholesterol values. In agreement with most previous studies we found a reduction of serum total cholesterol, LDL-cholesterol and HDLcholesterol values $1,17,19,21,23,24,30,31$ without any apparent effect by the fatty acid composition of the $\operatorname{diets}^{21,23,24}$. The decrease in HDL-cholesterol was entirely due to reduced $\mathrm{HDL}_{2}$-cholesterol whereas $\mathrm{HDL}_{3}$-cholesterol levels were actually increased. The changes of apoA-I and apoA-II parallelled those of $\mathrm{HDL}_{2^{-}}$and $\mathrm{HDL}_{3}$-cholesterol, respectively. Again, the effects of diets rich in MUFA and PUFA were quite similar.

HDL-subfractions have been studied in very few studies on low-fat diets. In our previous studies $\mathrm{HDL}_{2^{-}}$ cholesterol levels were decreased and $\mathrm{HDL}_{3}$-cholesterol levels unchanged ${ }^{30}$, with similar effects of two different levels of PUFA ${ }^{21}$. Kasim et al. ${ }^{33}$, in a 1-year study of low-fat intake, also observed a reduction in $\mathrm{HDL}$-cholesterol that affected the $\mathrm{HDL}_{2}$-subfraction. They found that post-heparin plasma lipoprotein lipase (LPL) activity correlated directly to the change of $\mathrm{HDL}_{2}$-cholesterol and inversely to the changes in $\mathrm{HDL}_{3}$ cholesterol and serum triglycerides.

An increase in triglycerides together with a reduction in $\mathrm{HDL}_{2}$-cholesterol and an increase in $\mathrm{HDL}_{3}$-cholesterol as found in our study suggests impaired removal of triglycerides from VLDL together with reduced conversion of smaller $\mathrm{HDL}_{3}$ into larger $\mathrm{HDL}_{2}$ particles. Both effects could be caused by reduced LPL activity ${ }^{33}$. 
Table 3 Serum lipoprotein lipid concentrations and body weight at the end of the study periods

\begin{tabular}{|c|c|c|c|c|c|}
\hline & Diet & Baseline & Intervention & Switchback & SEM \\
\hline Serum cholesterol $\left(\mathrm{mmoll}^{-1}\right)$ & $\begin{array}{l}\text { LF } \\
H P \\
H M\end{array}$ & $\begin{array}{l}5.45 \\
5.35 \\
5.68\end{array}$ & $\begin{array}{l}5.25^{2} \\
4.99^{2.5} \\
5.21^{2.5}\end{array}$ & $\begin{array}{l}5.33 \\
5.27 \\
5.65\end{array}$ & $\begin{array}{l}0.15 \\
0.15 \\
0.16\end{array}$ \\
\hline VLDL-cholesterol' $\left(\mathrm{mmoll}^{-1}\right)$ & $\begin{array}{l}L F \\
H P \\
H M\end{array}$ & $\begin{array}{l}0.41 \\
0.35 \\
0.32\end{array}$ & $\begin{array}{l}0.51^{4} \\
0.40 \\
0.33^{6}\end{array}$ & $\begin{array}{l}0.43 \\
0.35 \\
0.23\end{array}$ & $\begin{array}{l}0.05 \\
0.04 \\
0.05\end{array}$ \\
\hline LDL-cholesterol ${ }^{1}\left(\mathrm{mmoll}^{-1}\right)$ & $\begin{array}{l}\text { LF } \\
\text { HP } \\
\text { HM }\end{array}$ & $\begin{array}{l}3.34 \\
3.15 \\
3.50\end{array}$ & $\begin{array}{l}3.05^{2} \\
2.92^{4} \\
3.11^{2,5}\end{array}$ & $\begin{array}{l}3.08 \\
3.02 \\
3.47\end{array}$ & $\begin{array}{l}0.13-0.14 \\
0.12 \\
0.14\end{array}$ \\
\hline HDL-cholesterol ${ }^{1}\left(\mathrm{mmoll}^{-1}\right)$ & $\begin{array}{l}\text { LF } \\
\mathrm{HP} \\
\mathrm{HM}\end{array}$ & $\begin{array}{l}1.30 \\
1.35 \\
1.44\end{array}$ & $\begin{array}{l}1.16^{2,5} \\
1.24^{2,5} \\
1.29^{2,5}\end{array}$ & $\begin{array}{l}1.32 \\
1.40 \\
1.52\end{array}$ & $\begin{array}{l}0.06 \\
0.06 \\
0.06\end{array}$ \\
\hline $\mathrm{HDL}_{2}$-cholesterol ${ }^{1}\left(\mathrm{mmoll}^{-1}\right)$ & $\begin{array}{l}\text { LF } \\
\text { HP }\end{array}$ & $\begin{array}{l}0.84 \\
0.89 \\
0.90\end{array}$ & $\begin{array}{l}0.71^{2.5} \\
0.78^{2,5} \\
0.76^{2,5}\end{array}$ & $\begin{array}{l}0.83 \\
0.89 \\
0.98\end{array}$ & $\begin{array}{l}0.05 \\
0.04-0.05 \\
0.05\end{array}$ \\
\hline $\mathrm{HDL}_{3}$-cholesterol' $\left(\mathrm{mmoll}^{-1}\right)$ & $\begin{array}{l}\mathrm{LF} \\
\mathrm{HP}\end{array}$ & $\begin{array}{l}0.25 \\
0.24 \\
0.26\end{array}$ & $\begin{array}{l}0.28^{2.5} \\
0.28^{2,6} \\
0.28^{3}\end{array}$ & $\begin{array}{l}0.26 \\
0.26 \\
0.28\end{array}$ & $\begin{array}{l}0.01 \\
0.01 \\
0.01\end{array}$ \\
\hline Triglycerides $^{1}\left(\mathrm{mmoll}^{-1}\right)$ & $\begin{array}{l}\text { LF } \\
\mathrm{HP} \\
\mathrm{HM}\end{array}$ & $\begin{array}{l}1.44 \\
1.37 \\
1.31\end{array}$ & $\begin{array}{l}1.80^{3} \\
1.63^{4} \\
1.38^{7}\end{array}$ & $\begin{array}{l}1.69 \\
1.47 \\
1.26\end{array}$ & $\begin{array}{l}0.12 \\
0.12 \\
0.13\end{array}$ \\
\hline Body weight (kg) & $\begin{array}{l}\mathrm{LF} \\
\mathrm{HP} \\
\mathrm{HM}\end{array}$ & $\begin{array}{l}76.5 \\
73.6 \\
77.3\end{array}$ & $\begin{array}{l}75.6^{2} \\
73.2^{4} \\
76.3^{2}\end{array}$ & $\begin{array}{l}75.7 \\
73.3 \\
75.7\end{array}$ & $\begin{array}{l}2.6 \\
2.5 \\
2.7-2.8\end{array}$ \\
\hline
\end{tabular}

'Least squares means adjusted for baseline weight and change in body weight from baseline by repeated measures analysis of covariance; ${ }^{2} P<0.001 ;{ }^{3} P<0.01 ;{ }^{4} P<0.05$ for difference from baseline; ${ }^{5} P<0.001 ;{ }^{6} P<0.05$ for difference to switchback: ${ }^{7} P<0.05$ for difference to LF diet.

Other factors that may influence the composition of $\mathrm{HDL}$ are incorporation of cholesteryl esters into HDL, transfer of cholesteryl esters to other lipoproteins, the activity of hepatic triglyceride lipase ${ }^{34}$ and changes in apoprotein transpor ${ }^{35}$. Based on our analyses it is difficult to define the mode of the HDL-cholesterol lowering effect, because we did not measure putative associated factors such as the activities of LPL, hepatic lipase, lecithin-cholesteryl acyl transferase or cholesteryl ester transfer protein.

$A$ poB is the main apolipoprotein of both VLDL and LDL. A decrease in the concentration of apoB reflects decreased mass of apoB-containing lipoproteins. Increased apoB levels, like increased LDL-cholesterol levels, are associated with increased risk of coronary heart disease $(\mathrm{CHD})^{36,37}$. In the present study the HM diet reduced apoB levels significantly because it reduced LDL levels without increasing VLDL to the same extent as the other diets. ApoB has been considered an even stronger indicator of $\mathrm{CHD}$ risk than serum cholesterol ${ }^{36,37}$ and therefore the effect of HM diet on apoB deserves particular attention.

Serum triglyceride levels were significantly increased during the LF and HP diets and, as expected, the increase was largest after the LF diet that was lowest in fat (20 en\%). The lack of hypertriglyceridaemic effect on the HM diet, conversely, could not be expected on the basis of previous studies. Studies on dietary fat modification without concomitant reduction in fat intake either have shown no significant difference in the effect on serum triglycerides between PUFA and MUFA $^{4,38-43}$ or a triglyceride-lowering effect of high PUFA diet compared with high MUFA diet ${ }^{28,44}$. Howard et $a l^{24}$, in a carefully conducted comparison between MUFA and PUFA in connection with a moderate reduction in fat intake from 37 to $30 \mathrm{en} \%$, found a significant increasing trend in serum triglyceride levels parallelling an increase from 6 to $17 \mathrm{en} \%$ in the proportion of MUFA in the diets. The corresponding increments in serum triglycerides ranged from 5 to $12 \%$. In the present study the total fat intake was reduced from $33-34$ to 26 en\% during the HP and HM diets, and the relationship between the effects on triglycerides of MUFA and PUFA was the opposite to that found by Howard et al. ${ }^{24}$. The increments of mean serum triglyceride levels on the HP and LF diets were 19 and $25 \%$, respectively, but less than $5 \%$ on the HM diet. In our study dietary fibre intake was kept unchanged and thus the consumption of refined carbohydrates was increased during the low-fat diet periods. This may have augmented the rise in triglycerides but does not explain the differences between the diets that contained similar amounts of fibre.

Although the effects of MUFAs and PUFAs on serum 
Table 4 Serum apolipoprotein concentrations at the end of the study periods

\begin{tabular}{|c|c|c|c|c|c|}
\hline & Diet & Baseline & Intervention & Switchback & SEM \\
\hline $\mathrm{ApoB}^{1}\left(\mathrm{mgl}^{-1}\right)$ & $\begin{array}{l}\text { LF } \\
\text { HP } \\
\text { HM }\end{array}$ & $\begin{array}{l}1.04 \\
0.99 \\
1.03\end{array}$ & $\begin{array}{l}1.03 \\
0.94 \\
0.96^{3,6}\end{array}$ & $\begin{array}{l}0.98 \\
0.94 \\
1.03\end{array}$ & $\begin{array}{l}0.04 \\
0.04 \\
0.04\end{array}$ \\
\hline ApoA-1 $\left(\mathrm{mgl}^{-1}\right)$ & $\begin{array}{l}\text { LF } \\
\mathrm{HP} \\
\mathrm{HM}\end{array}$ & $\begin{array}{l}1.47 \\
1.50 \\
1.53\end{array}$ & $\begin{array}{l}1.34^{2,4} \\
1.37^{2,4} \\
1.41^{2,4}\end{array}$ & $\begin{array}{l}1.59 \\
1.67 \\
1.69\end{array}$ & $\begin{array}{l}0.05 \\
0.05 \\
0.05\end{array}$ \\
\hline ApoA- $\|^{1}\left(\mathrm{mgl}^{-1}\right)$ & $\begin{array}{l}\text { LF } \\
\mathrm{HP} \\
\mathrm{HM}\end{array}$ & $\begin{array}{l}0.28 \\
0.29 \\
0.29\end{array}$ & $\begin{array}{l}0.31^{2,5} \\
0.31^{3} \\
0.31^{3}\end{array}$ & $\begin{array}{l}0.29 \\
0.31 \\
0.30\end{array}$ & $\begin{array}{l}0.01 \\
0.01 \\
0.01\end{array}$ \\
\hline
\end{tabular}

LDL-cholesterol are rather similar, the effect of PUFAs appears to be slightly more pronounced according to a recent meta-analysis ${ }^{2}$. In our study no difference was found between a higher intake of PUFA during the HP diet and lower intakes during the two other diets. The difference in PUFA between the diets may have been insufficient or the relationship between PUFA intake and serum LDL-cholesterol is not linear as has been suggested on the basis of animal studies ${ }^{46}$.

The association between serum triglycerides and risk of CHD is a complex issue, and it is disputable whether the hypertriglyceridaemic effect of dietary fat reduction can be considered harmful ${ }^{20}$, particularly since a parallel reduction of LDL-cholesterol levels is achieved, and increased triglyceride levels seem to increase the risk of CHD particularly when associated with a high LDL/HDL-cholesterol ratio ${ }^{45,46}$.

\section{Quality assurance}

The participants were free-living couples who were provided with certain dietary fat products and some low-fat foods free of charge. Otherwise they purchased their food individually and prepared it at home following individual counselling and written instructions on how to use the fat products and how to reduce total fat intake. Repeated 3-day food records were used for monitoring dietary adherence. Feedback was prompt, because the data was stored and computed on the same day and the diets could be adjusted, if necessary, at the following weekly visit to the nutritionist. Consequently, the goals for total fat intake and fatty acid composition were exactly achieved. This was also supported by expected changes found in the serum fatty acid composition.

Another main goal of the dietary counselling was avoidance of weight reduction. Although we excluded persons with severe obesity, many of the participants were considerably overweight and a small degree of weight reduction could not be avoided during the lowfat diets. The mean loss of weight during the intervention periods was not clinically meaningful, less than $1 \mathrm{~kg}$. However, we adjusted the results of serum and lipoprotein lipid and apoprotein determinations for baseline weight and change of body weight from baseline. Therefore the results reflect effects of the dietary changes without the influence of body weight.

\section{Effect of background diet}

In 1980 we conducted in the same area a dietary intervention study with a similar design and with a diet that closely corresponded to the HP diet of the present study $^{25.26}$. In the previous study, a diet with $26 \mathrm{en} \%$ fat and $\mathrm{a} \mathrm{P} / \mathrm{S}$ ratio of 1.2 reduced mean serum total cholesterol levels by $25 \%$, affecting both LDL-cholesterol and HDL-cholesterol, whereas in the present study, diet HP with $26 \mathrm{en} \%$ fat and a P/S ratio of 1.1 reduced serum total cholesterol by $7 \%$ only. In both studies the mean serum cholesterol levels of the subjects at the end of the intervention periods were identical, $5.0 \mathrm{mmol}^{-1}$, but the the starting values were quite different, owing to different compositions of the background diets. In 1980 the background diet of people in North Karelia comprised $39 \mathrm{en} \%$ fat and a $\mathrm{P} / \mathrm{S}$ ratio of 0.15 compared with $33 \mathrm{en} \%$ fat and a $\mathrm{P} / \mathrm{S}$ ratio of 0.4 in the present study. This difference is in accordance with the dietary changes that have occurred in all parts of Finland during the past 20 years ${ }^{47}$. It has been found that persons with high serum cholesterol levels show a greater reduction in serum cholesterol in response to a dietary change than those with lower baseline levels ${ }^{48}$. Our studies indicate that people with a similar genetic background achieve similar serum cholesterol levels with similar diets and that the magnitude of reduction in serum cholesterol values is dependent on the magnitude of dietary change, determined by the quality of the background diet.

\section{Conclusion}

Low-fat diets had similar effects on serum and lipoprotein cholesterol levels and the composition of HDL irrespective of their fatty acid composition. The results support the view that reduction of total fat intake does not affect the serum LDL/HDL ratio favourably ${ }^{51}$. 
Furthermore, there was no additional benefit from decreasing dietary fat intake to $20 \%$ of energy compared with diets with $26 \mathrm{en} \%$ fat. According to the results, there might be a slight benefit in the form of reduced apoB levels and less increase in serum triglycerides from an increased proportion of monounsaturated fatty acids in reduced-fat diets.

\section{Acknowledgements}

This study was supported by grants from the United States Department of Agriculture, the Finnish Heart Foundation, and the Research Council for Health, Academy of Finland. The authors thank Pekka Puska for providing facilities, Päivi Kleemola for calculating the diets, Sanna Junkkonen, Anne Järvinen, Tuula Pöyhönen and Teija Vainikka for the dietary counselling, Tiina Vlasoff for managing the contacts with the participants, Mikko Virtanen for statistical advice, Jouko Sundvall for expert technical assistance in lipoprotein analysis, and the volunteers for excellent co-operation.

\section{References}

1 Insull W Jr, Silvers A, Hicks L, Probstfield JL. Plasma lipid effects of three common vegetable oils in reduced-fat diets of free-living adults. Am. J. Clin. Nutr. 1994; 60: 195-202.

2 Mensink RP, Katan MB. Effect of dietary fatty acids on serum lipids and lipoproteins: a meta-analysis of 27 trials. Arterioscler. Thromb. 1992; 12: 911-19.

3 Shepherd J, Packard CJ, Patsch JR, Gotto AM, Taunton OD. Effects of dietary polyunsaturated fat on properties of highdensity lipoproteins and metabolism of apolipoprotein A-I. J. Clin. Invest. 1978; 61: 1582-92.

4 Mattson FH, Grundy SM. Comparison of effects of dietary saturated, monounsaturated, and polyunsaturated fatty acids on plasma lipids and lipoproteins in man. J. Lipid Res. 1985; 26: 194-202.

5 Sundram K, Hayes KC, Siru OH. Dietary palmitic acid results in lower serum cholesterol than does a lauric-myristic acid combination in normolipemic humans. Am. J. Clin. Nutr. 1994; 59: 841-6.

6 Tholstrup T, Marckmann P, Jespersen J, Vessby B, Jart A, Sandström B. Effect on blood lipids, coagulation and fibrinolysis of a fat high in myristic acid and a fat high in palmitic acid. Am. J. Clin. Nutr. 1994; 60: 919-25.

7 Zock PL, de Vries JHM, Katan MB. Impact of myristic acid versus palmitic acid on serum lipid and lipoprotein levels in healthy women and men. Arterioscler. Thromb. 1994; 14: 567-75.

8 Temme EHM, Mensink RP, Hornstra G. Comparison of the effects of diets enriched in lauric, palmitis, or oleic acids on serum lipids and lipoproteins in healthy women and men. Am. J. Clin. Nutr. 1996; 63: 897-903.

9 MacDonald I, Braithwaite DM. The influence of dietary carbohydrates on the lipid pattern in serum and in adipose tissue. Clin. Sci. 1964; 27: 23-30.

10 Frayn KN, Kingman SM. Dietary sugars and lipid metabolism in humans. Am. J. Clin. Nutr. 1995; 62(suppl): 250S-63.

11 Mancini M, Mattock M, Rabaya E, Chait A, Lewis B. Studies on the mechanisms of carbohydrate-induced lipemia in normal men. Atherosclerosis 1973; 17: 445-54.

12 Ginsberg H, Olefsky JM, Kimmerling G, Crapo P, Reaven
GM. Induction of hypertriglyceridemia by a low-fat diet. $J$. Clin. Endocrinol. Metab. 1976; 42: 729-35.

13 Coulston AM, Liu GC, Reaven GM. Plasma glucose, insulin and lipid responses to high-carbohydrate low-fat diets in normal humans. Metabolism 1983; 32: 52-6.

14 Liu GC, Coulston AM, Reaven GM. Effect of high-carbohydrate-low-fat diets on plasma glucose, insulin and lipid responses in hypertriglyceridemic humans. Metabolism 1983; 32: 750-3

15 Garg A, Bantle JP, Henry RR, et al. Effects of varying carbohydrate content of diet in patients with non-insulindependent diabetes mellitus. J. Am. Med. Assoc. 1994; 271: 1421-8.

16 Lichtenstein AH, Ausman LM, Carrasco W, Jenner JL, Ordovas JM, Schaefer EJ. Short-term consumption of a low-fat diet beneficially affects plasma lipid concentrations only when accompanied by weight loss. Anterioscler. Tbromb. 1994; 14: 1751-60.

17 Schaefer EJ, Lichtenstein AH, Lamon-Flava S, et al. Body weight and low-density lipoprotein changes after consumption of a low-fat ad libitum diet. J. Am. Med. Assoc. 1995; 274: $1450-5$

18 Rivellese AA, Auletta P, Marotta G, et al. Long term metabolic effects of two dietary methods of treating hyperlipidaemia. Br. Med.J. 1994; 308: 227-31.

19 Ullmann D, Connor WE, Hatcher LF, Connor SL, Flavell DP. Will a high-carbohydrate, low-fat diet lower plasma lipids without producing hypertriglyceridemia? Arterioscler. Thromb. 1991; 11: 1059-67.

20 Bierman E. New dimensions in carbohydrates. Concluding remarks. Am. J. Clin. Nutr. 1995; 61(suppl): 1009S-11.

21 Kuusi T, Ehnholm C, Huttunen JK, et al. Concentration and composition of serum lipoproteins during a low-fat diet at two levels of polyunsaturated fat. J. Lipid Res. 1985; 26: 3607.

22 Judd JT, Oh SY, Henning B, Dupont J, Marshall MW. Effects of low fat diets differing in degree of fat unsaturation on plasma lipids, lipoproteins, and apolipoproteins in adult men. J. Am. Coll. Nutr. 1988; 7: 223-34.

23 Sanders K, Johnson L, O'Dea K, Sinclair AJ. The effect of dietary fat level and quality on plasma lipoprotein lipids and plasma fatty acids in normocholesterolemic subjects. Lipids 1994; 29: 129-38.

24 Howard BV, Hannah JS, Heiser CC, et al. Polyunsaturated fatty acids result in greater cholesterol lowering and less triacylglycerol elevation than do monounsaturated fatty acids in a dose-response comparison in a multiracial study group. Am. J. Clin. Nutr. 1995; 62: 392-402.

25 Pietinen P, Dougherty R, Mutanen M, Leino U, Moisio S, Iacono J, Puska P. Dietary intervention study among 30 freeliving families in Finland. J. Am. Diet. Assoc. 1984; 84: 313-18.

26 Ehnholm C, Huttunen JK, Pietinen P, et al. Effect of diet on serum lipoproteins in a population with a high risk of coronary heart disease. N. Engl. J. Med. 1982; 307: 850-5.

27 Havel RJ, Eder HA, Bragdon JH. The determination and chemical composition of ultracentrifugally separated lipoproteins in human serum. J. Clin. Invest. 1955; 34: 1345-53.

28 Valsta $L M$, Jauhiainen $M$, Aro A, Katan MB, Mutanen $M$. Effects of a monounsaturated rapeseed oil and a polyunsaturated sunflower oil diet on lipoprotein levels in humans. Anterioscler. Thromb. 1992; 12: 50-7.

29 Riepponen P, Marniemi J, Rautaoja T. Determination of apolipoproteins $\mathrm{A}-\mathrm{I}$ and $\mathrm{B}$ in serum. Scand. J. Clin. Lab. Invest. 1987; 47: 739-44.

30 Crowder MJ, Hand DJ. Analysis of Repeated Measures. London: Chapman and Hall, 1990.

31 Ehnholm C, Huttunen JK, Pietinen P, et al. Effect of a diet low in saturated fatty acids on plasma lipids, lipoproteins, and HDL subfractions. Arteriosclerosis 1984; 4: 265-9.

32 Sacks FM, Handysides GH, Marais GE, Rosner B, Kass EH 
Effects of a low-fat diet on plasma lipoprotein levels. Arch. Intern. Med. 1986; 146: 1573-7.

33 Kasim SE, Martino S, Kim P-N, et al. Dietary and anthropometric determinants of plasma lipoproteins during a longterm low-fat diet in healthy women. Am. J. Clin. Nutr. 1993; 57: 146-53.

34 Eckel RH. Lipoprotein lipase: a multifactorial enzyme relevant to common metabolic disease. N. Engl. J. Med. 1989; 320: $1060-8$.

35 Kuusi T, Saarinen P, Nikkilä EA. Evidence for the role of hepatic endothelial lipase in the metabolism of high density lipoprotein in man. Atberosclerosis 1980; 36: 589-604.

36 Brinton EA, Eisenberg S, Breslow JL. A low-fat diet decreases high density lipoprotein (HDL) cholesterol levels by decreasing HDL apolipoprotein transport rates. J. Clin. Invest. 1990; 85: 144-51.

37 Avogaro P, Bittolo Bon G, Cazzolato G, Quinci GB. Are apolipoproteins better discriminators than lipids for atherosclerosis? Lancet 1979; 1: 901-3.

38 Kwiterovich PO Jr, Coresh J, Smith HH, Bachorik PS, Derby CA, Pearson TA. Comparison of the plasma levels of apolipoproteins B and A-I, and other risk factors in men and women with premature coronary artery disease. Am.J. Cardiol. 1992; 69: 1015-21.

39 Sirtori CR, Tremoli E, Gatti E, et al. Controlled evaluation of fat intake in the Mediterranean diet: comparative activities of olive oil and corn oil on plasma lipids and platelets in highrisk patients. Am.J. Clin. Nutr. 1986; 44: 635-42.

40 McDonald BE, Gerrard JM, Bruce VM, Corner EJ. Comparison of the effect of canola oil and sunflower oil on plasma lipids and lipoproteins and on in vivo thromboxane $A_{2}$ and prostacyclin production in healthy young men. Am. J. Clin. Nutr. 1989; 50: 1382-8.

41 Mensink RP, Katan MB. Effect of a diet enriched with monounsaturated or polyunsaturated fatty acids on levels of low-density and high-density lipoprotein cholesterol in healthy women and men. N. Engl. J. Med. 1989; 321: 436-41.
42 Dreon DM, Vranizan KM, Krauss RM, Austin MA, Wood PD. The effects of polyunsaturated fat vs. monounsaturated fat on plasma lipoproteins. J. Am. Med. Assoc. 1990; 263: 24626.

43 Wardlaw GM, Snook JT, Lin MC, Puangco MA, Kwon JS. Serum lipid and apoprotein concentrations in healthy men on diets enriched in either canola oil or safflower oil. Am.J. Clin. Nutr. 1991; 54: 104-10.

44 Nydahl MC, Gustafsson I-B, Vessby B. Lipid-lowering diets enriched with monounsaturated or polyunsaturated fatty acids but low in saturated fatty acids have similar effects on serum lipid concentrations in hyperlipidemic patients. $\mathrm{Am}$. J. Clin. Nutr. 1994; 59: 115-22.

45 Gustafsson I-B, Vessby B, Öhrvall M, Nydahl M. A diet rich in monounsaturated rapeseed oil reduces the lipoprotein cholesterol concentration and increases the relative content of $n-3$ fatty acids in serum in hyperlipidemic subjects. Am.J. Clin. Nutr. 1994; 59: 667-74.

46 Hayes KC, Khosla P. Dietary fatty acid thresholds and cholesterolemia. FASEB J. 1992; 6: 2600-7.

47 Manninen V, Tenkanen L, Koskinen P, et al. Joint effects of serum triglyceride and LDL cholesterol concentrations on coronary heart disease risk in the Helsinki Heart Study: implications for treatment. Circulation 1992; 85: 37-45.

48 Assmann G, Schulte H. Relation of high-density lipoprotein cholesterol and triglycerides to incidence of atherosclerotic coronary artery disease (the PROCAM experience). Am. J. Cardiol. $1992 ;$ 70: 733-7.

49 Pietinen $P$, Vartiainen $E$, Seppänen $R$, Aro A, Puska $P$. Changes in diet in Finland from 1972 to 1992. Impact on coronary heart disease risk. Prev. Med. 1996; 25: 243-50.

50 Denke MA, Frantz. ID. Response to a cholesterol-lowering diet: efficacy is greater in hypercholesterolemic subjects even after adjustment for regression to the mean. Am. J. Med. 1993; 94: 626-31.

51 Katan MB, Grundy SM, Willett WC. Beyond low-fat diets. N. Engl.J. Med. 1997; 337: 563-6. 